\title{
A new species of Litarachna (Acari, Hydrachnidia, Pontarachnidae) from a Caribbean mesophotic coral ecosystem
}

\author{
Vladimir Pešićl, Tapas Chatterjee², Monica Alfaro³, Nikolaos V. Schizas ${ }^{4}$
}

I Department of Biology, University of Montenegro, Cetinjski put b.b., 81000 Podgorica, Montenegro 2 Department of Biology, Indian School of Learning, I.S.M. Annexe, P.O. - I.S.M., Dhanbad-826004, Jharkhand, India 3 Department of Biology, University of Puerto Rico, Mayagüez, Call Box 9000, Mayagüez, PR 00681, USA 4 Department of Marine Sciences, University of Puerto Rico, Mayagüez, Call Box 9000, Mayagüez, PR 00681, USA

Corresponding author: Vladimir Pešić (vladopesic@gmail.com)

Academic editor: Enrico de Lillo | Received 15 June 2014 | Accepted 1 July 2014 | Published 15 July 2014

http://zoobank.org/F889FA1C-B58B-46E4-88F2-269758A8A9CE

Citation: Pešić V, Chatterjee T, Alfaro M, Schizas NV (2014) A new species of Litarachna (Acari, Hydrachnidia, Pontarachnidae) from a Caribbean mesophotic coral ecosystem. ZooKeys 425: 89-97. doi: 10.3897/zookeys.425.8110

\begin{abstract}
New records of pontarachnid mites (Acari: Hydrachnidia) from the Caribbean island of Puerto Rico are presented. Litarachna lopezae sp. n., from substrata collected from Bajo de Sico, a mesophotic coral reef ecosystem in Mona Passage off Puerto Rico, is described as new to science. The new species was collected from nearly $70 \mathrm{~m}$ depth, the greatest depth from which pontarachnid mites have been found until now. In addition, a Litarachna sp. was also found in association with the tube of the polychaete Sabellastarte magnifica (Shaw, 1800) at the shallow waters of north Puerto Rico.
\end{abstract}

\section{Keywords}

Water mites, taxonomy, marine environment, Puerto Rico, biodiversity

\section{Introduction}

The water mite family Pontarachnidae Koenike, 1910, the only family of the Hydrachnidia occurring in the marine environment, represents a well-defined monophyletic clade. Most species are reported from the littoral zone of marine waters in tropical

Copyright Vladimir Pešić et al. This is an open access article distributed under the terms of the Creative Commons Attribution License (CC BY 4.0), which permits unrestricted use, distribution, and reproduction in any medium, provided the original author and source are credited. 
and subtropical areas. In Australia and South Africa species have been recorded from estuarine freshwaters, and two species in South Korea are known to live only in marine interstitial environments (Pešić 2013). Nothing is known about the life cycle of the Pontarachnidae. So far, three species are known from the Caribbean Sea, i.e. Litarachna degiustii Cook, 1958 (Bimini, Bahamas - Cook 1958, Netherlands Antilles - Pešić et al. 2008), L. caribica Pešić, Chatterjee \& Schizas, 2008 (Netherlands Antilles - Pešić et al. 2008) and Pontarachna nemethi Pešić, Chatterjee \& Schizas, 2012 (Vieques Island of Puerto Rico - Pešić et al. 2012b).

Mesophotic coral ecosystems (MCEs) are light-dependent habitats dominated by macroalgae, sponges and scleractinian corals and are found on the insular and continental slopes of Caribbean islands between 30 and $100 \mathrm{~m}$ (Locker et al. 2010). Even at the lower depth range $(70-100 \mathrm{~m})$, there is enough light for photosynthesis to take place enhancing the growth of several scleractinian coral species (e.g. Agaricia spp., Montastraea spp.) and algae. The MCEs of Puerto Rico represent a potential biodiversity hotspot for marine arthropods and so far 2 mites (Pešić et al. 2012b, current paper), 1 harpacticoid copepod (Corgosinho and Schizas 2013) and 9 cumaceans (Petrescu et al. 2012, 2013, 2014a, b) new to science have been described.

In this paper we describe a new species, Litarachna lopezae sp. n. collected during the second of 3 mesophotic cruises (2010-2012) organized by the University of Puerto Rico at Mayagüez (UPRM), the Caribbean Coral Reef Institute (CCRI) and the Department of Marine Sciences (DMS) of UPRM (Sherman et al. 2013). We also describe the female specimen of a tentative new species which was found in association with the polychaete Sabellastarte magnifica (Shaw, 1800) from a shallow water habitat in north Puerto Rico.

\section{Materials and methods}

Material examined in the present study was collected from Bajo de Sico $\left(18^{\circ} 14^{\prime} 41.676^{\prime \prime} \mathrm{N}, 67^{\circ} 24^{\prime} 45.791^{\prime \prime W}\right)$, a mesophotic reef formation located in Mona Passage off Puerto Rico. During the 2011 Mesophotic Cruise of DMS-UPRM, divers equipped with Tri-Mix Rebreathers collected substrata (loose rubble, corals, sponges, algae) from $69.5 \mathrm{~m}$ depth and placed them in sealed plastic bags. As soon as the samples returned to the surface they were placed on a $1 \mathrm{~mm}$ and $0.125 \mathrm{~mm}$ sieves. Samples were washed with filtered seawater and the portion of fauna retained on the $0.125 \mathrm{~mm}$ sieve was preserved in $95 \%$ ethanol. One specimen was collected from Rio Grande, Puerto Rico $\left(18^{\circ} 25^{\prime} 11.86^{\prime \prime N}, 65^{\circ} 47^{\prime} 40.43^{\prime \prime W}\right)$ from marine littoral. This specimen was found while tubes of the polychaete Sabellastarte magnifica were washed into a $0.063 \mathrm{~mm}$ sieve. Mites and other fauna were extracted by Alexandra Galindo and the fourth author with the aid of a stereomicroscope and placed back in 95\% ethanol. Slide-mounting was done in Hoyer's fluid and water mites were treated in laboratory as decribed by Gerecke et al. (2007). All drawings were prepared using a drawing tube attached to a Olympus BX43 brightfield microscope. The holotype 
and paratypes are planned to be deposited in the Museum of Natural History of Montenegro in Podgorica.

All measurements are given in $\mu \mathrm{m}$. The following abbreviations are used: $\mathrm{Cx}-\mathrm{I}=$ first coxae, $\mathrm{dL}=$ dorsal length, $\mathrm{H}$ = height, $\mathrm{L}=$ length, $\mathrm{I} / \mathrm{II} / \mathrm{III} / \mathrm{IV}-\mathrm{L}-1-6$ = first to sixth segments of the first to fourth legs, $\mathrm{P}-1$ to $\mathrm{P}-5=$ palp segments 1 to $5, \mathrm{vL}=$ ventral length, $\mathrm{W}=$ width.

\section{Systematics}

\section{Genus Litarachna Walter, 1925}

\section{Litarachna lopezae sp. $\mathrm{n}$.}

http://zoobank.org/4C577A5A-9287-476A-A611-12DD3667687C

Figs $1 \mathrm{~A}-\mathrm{B}, 2,3 \mathrm{~A}-\mathrm{E}$

Type series. Holotype male, dissected and slide mounted, Puerto Rico, Bajo de Sico, $18^{\circ} 14^{\prime} 41.676 " \mathrm{~N}, 67^{\circ} 24^{\prime} 45.791 " \mathrm{~W}$, depth $69.5 \mathrm{~m}, 20$. iv.2011. Paratypes: three males, two females, one deutonymph, same data as holotype, one male and one female dissected and slide mounted.

Diagnosis. Adults. Idiosoma small (L 250-300 $\mu \mathrm{m}$ ); first coxal plates fused; glandularium-like structure fused with Cx-IV, a pair of small platelets with (according to Wiles et al. 2002) coxoglandularia 4 and associated setae free in the integument near the lateral posterior apodemes of Cx-IV; ventral margin of P-4 with a setal tubercle and a small peg-like seta.

Description. General features - First coxal plates fused medially; suture lines $\mathrm{Cx}-\mathrm{I} /$ II complete, suture line Cx-II/III and Cx-III/IV incomplete. Posterior margin of CxIV with two pairs of apodemes of moderate length, the medial longer than lateral ones, extending beyond anterior margin of genital field; glandularium-like structure on the outer side of lateral posterior apodemes of Cx-IV, fused with the fourth coxal plates; a pair of small platelets with coxoglandularia 4 and associated setae free in the integument near the lateral posterior apodemes of $\mathrm{Cx}$-IV; posterior to the genital field a pair of platelets with three pores, and three pairs of small wheel-like acetabula, with relatively few radiating spokes. Excretory pore unsclerotized, near posterior end of idiosoma. Palp: ventral margin of P-2 concave without extension; ventral margin of P-4 with a setal tubercle and a small peg-like seta. Legs (Fig. 3C): swimming seta numbers: III-L-5, 1; IV-L-4, 1; IV-L-5, 1. Male: genital field consisting of a sclerotized ring with four pairs of setae; four pairs of perigenital setae free in integument around genital field. Female: pre and postgenital sclerites bowed.

Deutonymph. As in adults but lacking genital field; glandularium-like structure free in the integument on the outer side of lateral posterior apodemes of Cx-IV.

Measurements. Male (holotype, in parentheses paratype, $\mathrm{n}=1$ ) - Idiosoma (ventral view, Figs 1A, 2) L 258 (268), W 234 (230); coxal field L 116 (106), Cx-III W 154 


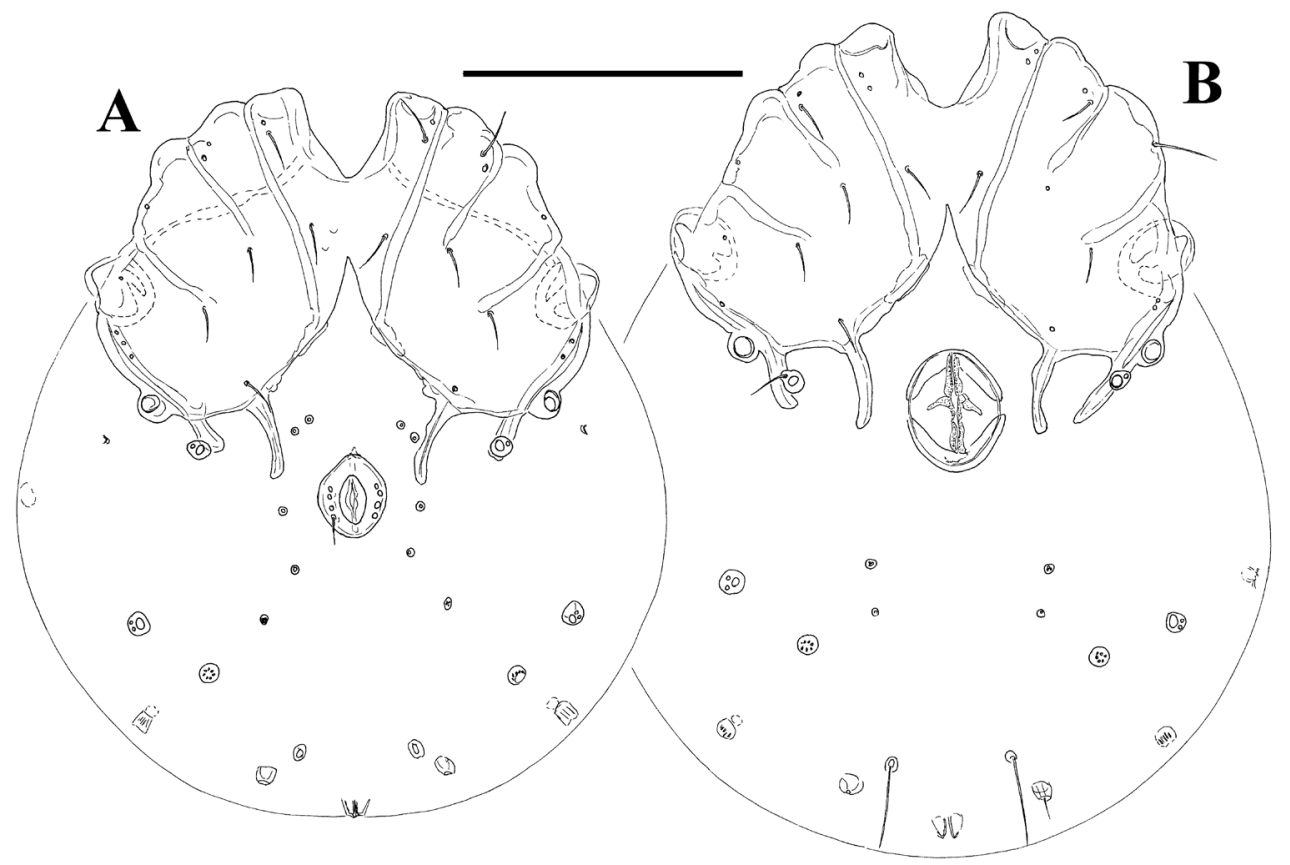

Figure I. Litarachna lopezae sp. n., Bajo de Sico (A male, B female): idiosoma, ventral view. Scale bar $=100 \mu \mathrm{m}$.

(158); ring-shaped genital plate L 29 (31), W 25 (24); chelicera total L (116). Palp (Figs 3A-B): total L 183 (182), dL/H, L/H ratio: P-1, 17/12, 1.38 (16/12, 1.3); P-2, 52/28, 1.89 (53/29, 1.86); P-3, 22/23, 0.97 (23/23, 1.0); P-4, 67/17, 4.0 (67/17, 4.0); P-5, 25/10, 2.5 (23/10. 2.4); dL P-2/P-4 ratio 0.78 (0.79); dL of I-L-3-6: 35, 34, 53 (52), 71 (73); I-L-6 H 17 (15), I-L-6 dL/H ratio 4.3 (4.7); dL of IV-L-2-6: 35, 42, $68,88,88$.

Female - Idiosoma (ventral view, Fig. 1B) L 295, W 237; coxal field L 118, Cx-III W 160; genital field L 44, pregenital sclerite W 34, postgenital sclerite W 35; chelicera total L 134. Palp (Fig. 3D): total L 190, dL/H, L/H ratio: P-1, 16/12, 1.3; P-2, 59/31, 1.9; P-3, 19/24, 0.78; P-4, 71/17, 4.2; P-5, 25/11, 2.35; dL P-2/P-4 ratio 0.83; dL of IV-L-4-6: 74, 91, 92.

Deutonymph - Idiosoma (ventral view, Fig. 3E) L 220, W 190; coxal field L 90, Cx-III W 119; palp: total L 129, dL/H, L/H ratio: P-1, 13/9, 1.4; P-2, 34/20, 1.7; P-3, 17/17, 1.0; P-4, 48/13, 3.7; P-5, 17/7, 2.46 dL P-2/P-4 ratio 0.71.

Etymology. This species is named after the famous Puerto Rican singer Jennifer Lopez.

Remarks. Six Litarachna species have their first coxal plates fused, i.e., L. degiustii Cook, 1958 (Caribbean Sea - Cook 1958, Pešić et al. 2008), L. amnicola Cook, 1986 (Tasmania - Cook 1986, Pešić and Smit 2009), L. brasiliensis Smit, 2007 (Brazil - Smit 2007), L. caribica Pešić, Chatterjee \& Schizas, 2008 (Caribbean Sea - Pešić et al. 2008), 


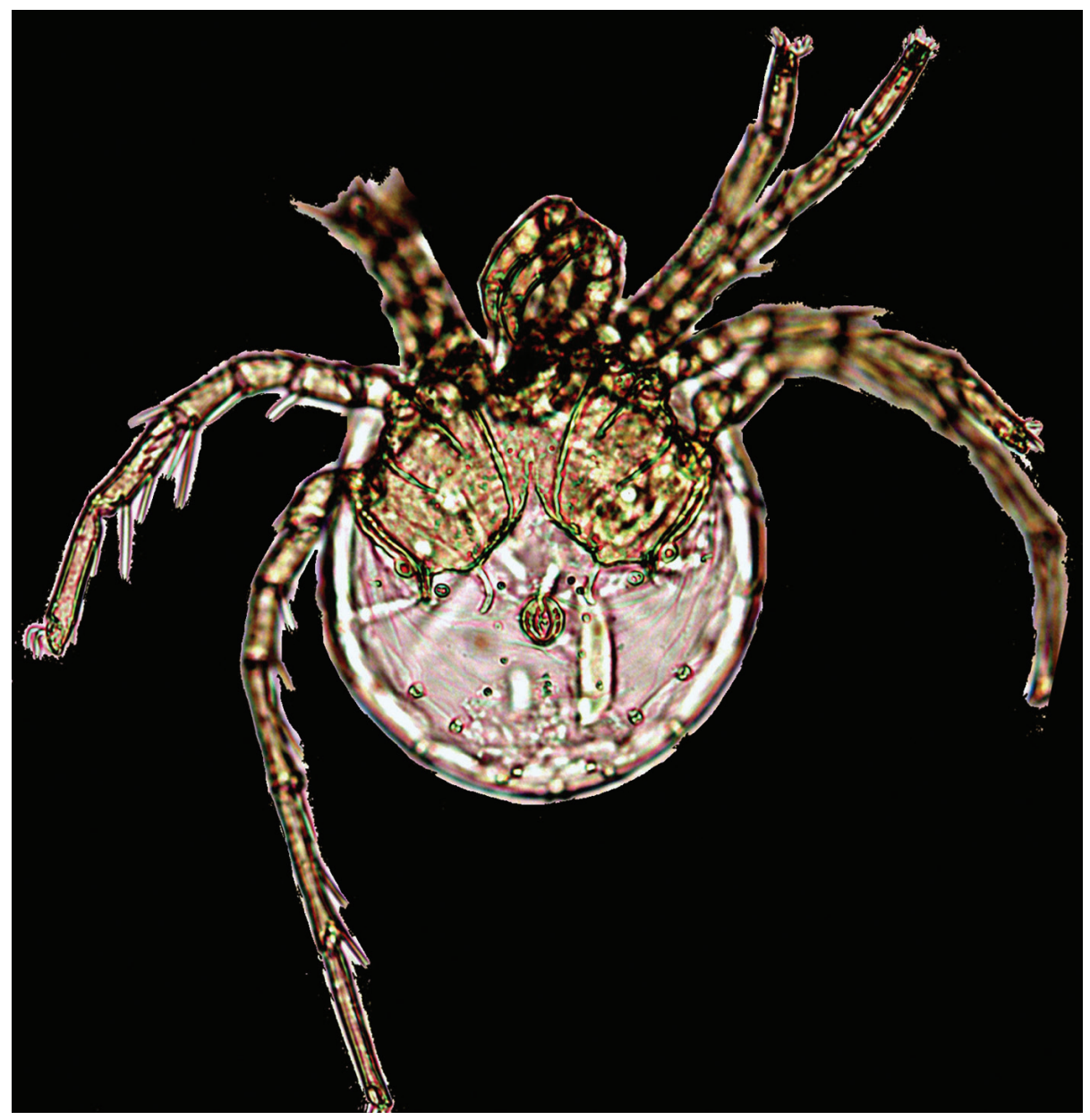

Figure 2. Photograph of Litarachna lopezae sp. n., male, Bajo de Sico: ventral view.

L. indica Pešić, Chatterjee \& Ingole, 2012 (West Indian coast - Pešić et al. 2012a) and L. minuta Pešić, Chatterjee \& Marshall, 2013 (Brunei Darussalam - Pešić et al. 2013).

Due to the glandularium-like structure fused with posterior margin of Cx-IV, $L$. lopezae sp. n. most closely resembles to L. minuta, a species known from a single female from Brunei Bay, but differs by a pair of small platelets with coxoglandularia 4 and associated setae lying free in the integument, not fused with Cx-IV (fused in L. minuta).

Moreover, peg-like seta at the base of P-4 ventral projection separates new species from L. minuta and other species with fused first coxal plates.

Habitat. The mites were collected from $69.5 \mathrm{~m}$ depth. The greatest depth at which pontarachnid mites have been recorded previously was reported by Pešić et al. (2012b) who found Pontarachna nemethi in a mesophotic coral ecosystem near Vieques Island of Puerto Rico at $67 \mathrm{~m}$ depth.

Distribution. Only known from the type locality. 


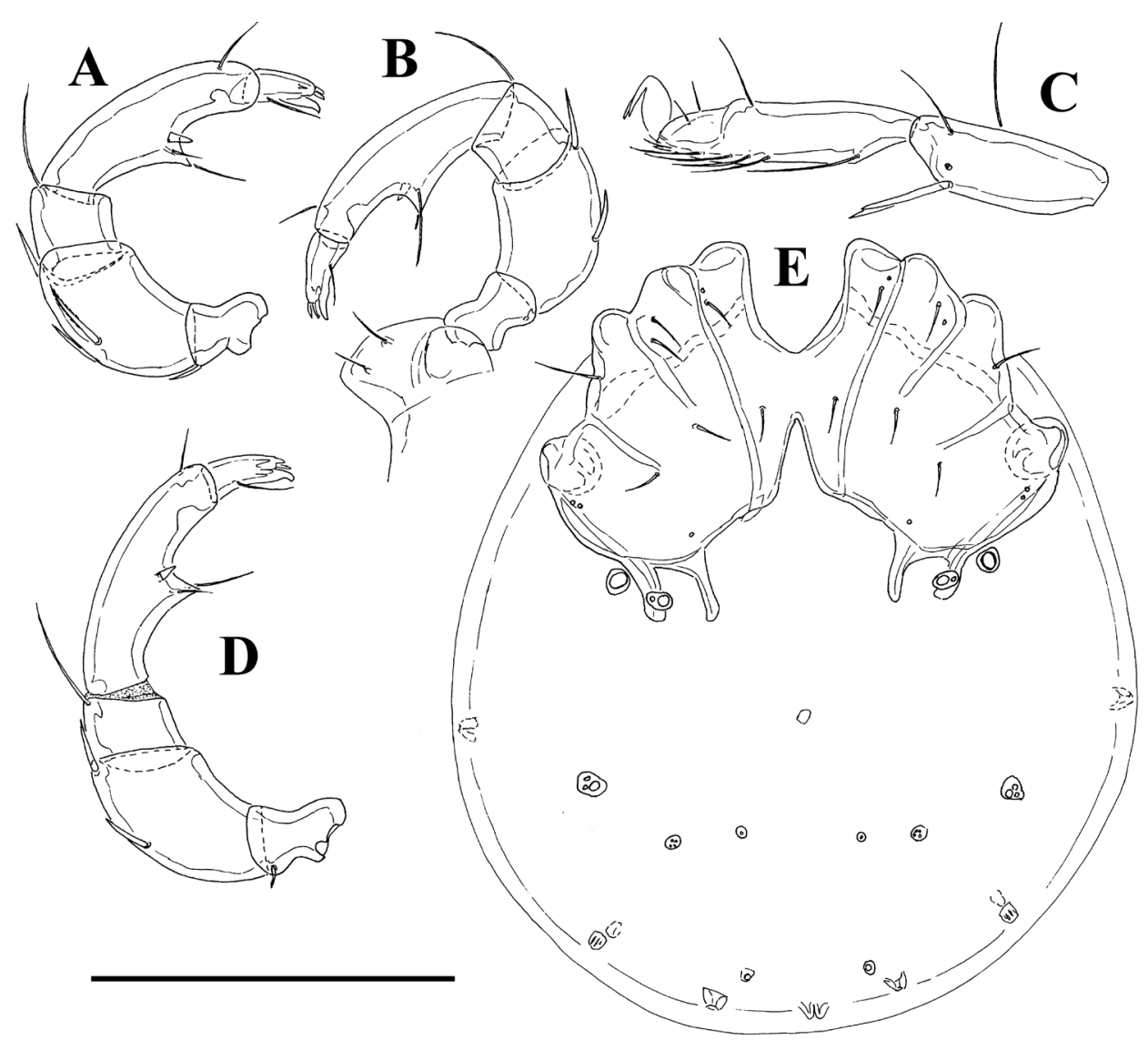

Figure 3. Litarachna lopezae sp. n., Bajo de Sico (A-C = male, $\mathrm{D}=$ female, $\mathrm{E}=$ deutonymph): A-B, $\mathbf{D}$ palp C I-L-5-6 E idiosoma, ventral view. Scale bar $=100 \mu \mathrm{m}$.

\section{Litarachna sp.}

Fig. 4A-D

Material examined. Puerto Rico, Rio Grande, 18² $25^{\prime} 11.86^{\prime \prime N}, 65^{\circ} 47^{\prime} 40.43^{\prime \prime W}$, depth $0.5 \mathrm{~m}$, 15.ii.2014, one female, dissected and slide mounted.

Description. Female. General features - Cx-I separated medially; suture lines Cx-I/ II and Cx-III/IV complete, suture line Cx-II/III incomplete; posterior margin of $\mathrm{Cx}$ IV with two pairs of apodemes of moderate length, the medial broad and longer than lateral ones, extending beyond posterior margin of genital field; pair of small platelets with coxoglandularia 4 and associated setae free in the integument between the posterior apodemes of $\mathrm{Cx}-\mathrm{IV}$; pre- and post-genital sclerites strongly bowed, almost touching each other, pregenital sclerite arrow-shaped (Fig. 4C); posterior to the genital field a pair of platelets with three pores and a glandularium-like structure, and three pairs of small wheel-like acetabula, with relatively few radiating spokes; excretory pore 


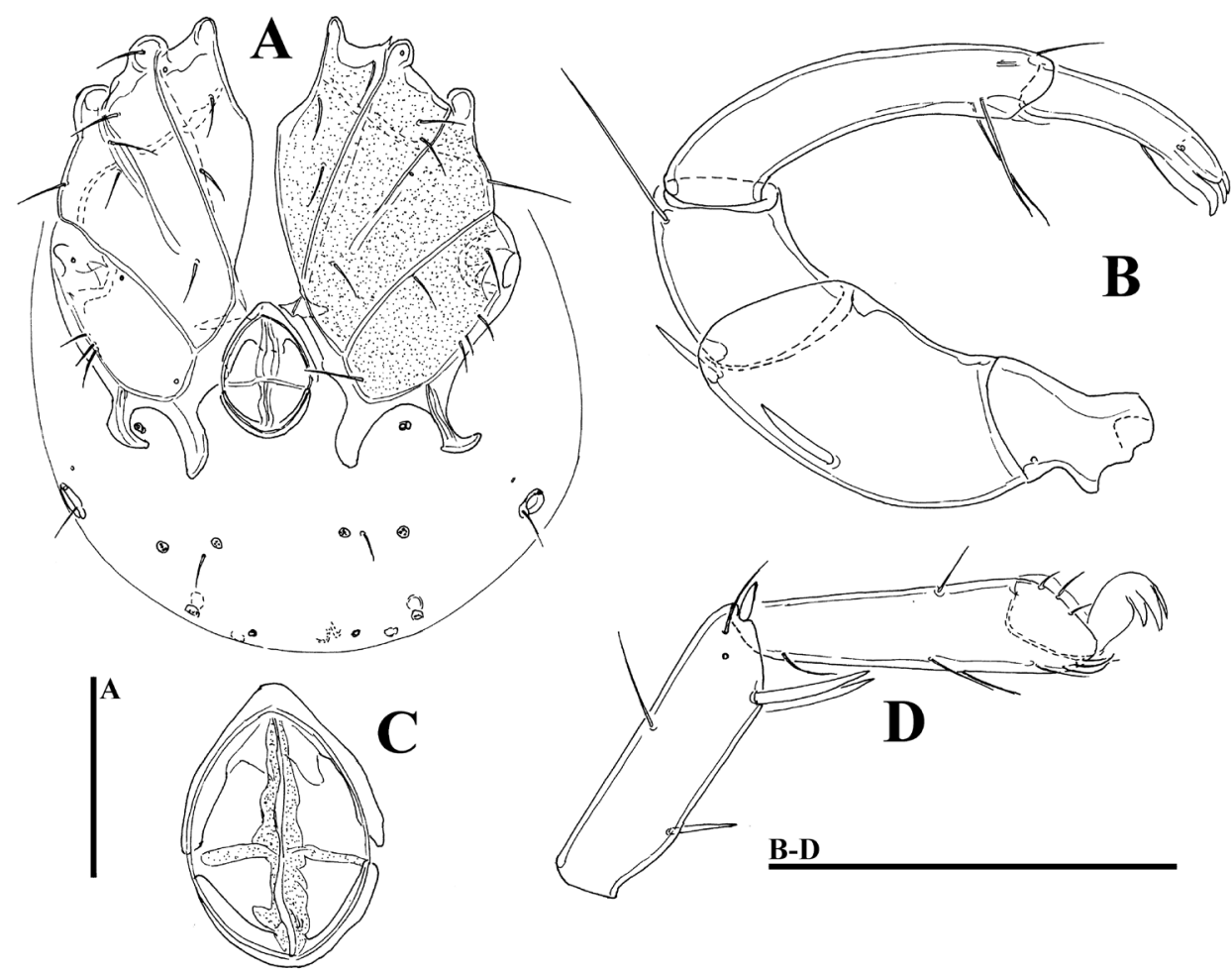

Figure 4. Litarachna sp., female, Rio Grande: A idiosoma, ventral view B palp C genital field D I-L-5 and -6 . Scale bars $=100 \mu \mathrm{m}$.

unsclerotized, near posterior end of idiosoma. Palp: P-2 ventral margin concave, P-5 longer than $1 / 2$ of P-4. Legs (Fig. 4D): swimming seta numbers: IV-L-4, 1; IV-L-5, 1.

Measurements - Idiosoma (ventral view, Fig. 4A) L 323, W 269; coxal field L 197, Cx-III W 219; genital field L 71, pregenital sclerite W 50, postgenital sclerite W 46; chelicera total L. Palp (Fig. 4B): total L 307, dL/H, L/H ratio: P-1, 18/19, 0.97; P-2, 87/44, 1.98; P-3, 46/34, 1-36; P-4, 100/24, 4.1; P-5, 56/14, 4.0, dL P-2/P-4 ratio 0.87; dL of I-L-2-6: 42, 48, 55, 81, 90; I-L-6 H 23, I-L-6 dL/H ratio 3.9; dL of IVL-2-6: 49, 58, 91, 106, 108.

Remarks. The single female from Puerto Rico closely resembles Litarachna communis Walter, 1925, a species widespread in Mediterranean (Pešić et al. 2012a), but clearly differs in having more bowed, arrow-shaped pregenital sclerite. Most probably we are dealing with an undescribed species, but since male specimens were not available, a final decision cannot be made.

Habitat. The single specimen was collected from a tube of a live Sabellastarte magnifica (Shaw, 1800), a large, tubiforous shallow water polychaete of the Caribbean. The polychaete specimens were collected together with their tubes and were washed in a 0.063 $\mathrm{mm}$ sieve to examine the associated fauna. Our sampling strategy limits our conclusions whether the female mite was collected from inside or outside the polychaete tube. 


\section{Acknowledgements}

The fourth author (NVS) acknowledges the NOAA's Center for Sponsored Coastal Ocean Research Award (No. NA06NOS4780190) to the Caribbean Coral Reef Institute (CCRI) of UPRM. Funds for the research cruises were provided by NOAA grants (NA10NOS4260223, NA11NOS4260157, NA11NOS4260184) to CCRI of UPRM. NVS also thanks the Trimix Rebreather Diving Team: Ivonne Bejarano, Milton Carlo, Michael Nemeth, Doug Kesling, Clark Sherman, and Hector Ruiz for the collection of samples and Alexandra Galindo for helping in sample sorting.

\section{References}

Cook DR (1958) A new species of Litarachna from the British West Indies (Acarina: Pontarachnidae). Proceedings of The Entomological Society of Washington 60: 19-22.

Cook DR (1986) Water mites from Australia. Memoirs of the American Entomological Institute 40: $1-568$.

Corgosinho PHC, Schizas NV (2013) Archeolourinia shermani, a new genus and species of Louriniidae (Copepoda: Harpacticoida) from a Caribbean mesophotic zone. Journal of the Marine Biological Association of the United Kingdom 93(3): 651-657. doi: 10.1017/ S0025315412001336

Gerecke R, Weigmann G, Wohltmann A, Wurst E (2007) Order Acari - General introduction and key to major groups. In: Gerecke R (Ed) Süßwasserfauna von Mitteleuropa, Vol. 7, 2-1. Elsevier GmbH, Spektrum Akademischer Verlag, München, 14-57.

Locker SD, Armstrong RA, Battista TA, Rooney JJ, Sherman C, Zawada DG (2010) Geomorphology of mesophotic coral ecosystems: current perspectives on morphology, distribution, and mapping strategies. Coral Reefs 29: 329-345. doi: 10.1007/s00338-010-0613-6

Petrescu I, Chatterjee T, Schizas NV (2012) New genus and new species of Cumacea (Crustacea: Peracarida) from the mesophotic coral ecosystem of SW Puerto Rico, Caribbean. Zootaxa 3476: 55-61.

Petrescu I, Chatterjee T, Schizas NV (2013) Two new species of the genus Cumella (Crustacea: Cumacea: Nannastacidae) associated with mesophotic reefs of Puerto Rico and St. Croix, Caribbean Sea. Cahiers de Biologie Marine 54: 257-262.

Petrescu I, Chatterjee T, Schizas NV (2014a) Three new Nannastacidae (Crustacea: Cumacea) species from a Caribbean mesophotic ecosystem. Zootaxa 3765: 360-370. doi: 10.11646/ zootaxa.3765.4.4

Petrescu I, Chatterjee T, Schizas NV (2014b) New species of Cumella (Crustacea: Cumacea: Nannastacidae) from mesophotic habitats of Mona Island, Puerto Rico, Caribbean Sea. Cahiers de Biologie Marine 55: 183-189.

Pešić V, Chatterjee T, Schizas N (2008) Marine water mites (Acari: Hydrachnidia: Pontarachnidae) from the Caribbean Sea, with description of one new species. Cahiers de Biologie Marine 49: 253-259. 
Pešić V, Smit H (2009) New records of water mites (Acari: Hydrachnidia) from Tasmania, with descriptions of three new species. Zootaxa 2070: 53-62.

Pešić V, Chatterjee T, Ingole B, Velip D, Pavićević A (2012a) A new species of Litarachna Walter, 1925 (Acari: Hydrachnidia) from the West Indian Coast, with a discussion on the diversity of the family Pontarachnidae Koenike, 1910. Cahiers de Biologie Marine 53: 547-553.

Pešić V, Chatterjee T, Schizas N (2012b) A new species of Pontarachna (Acari, Hydrachnidia, Pontarachnidae) from a mesophotic coral ecosystem off Vieques Island, Puerto Rico, Caribbean Sea. Zootaxa 3440: 63-67.

Pešić V (2013) Pontarachnid mites from marine interstitial, with a description of three new species from South Korea (Acari: Hydrachnidia: Pontarachnidae). Zootaxa 3701(1): 83-92. doi: 10.11646/zootaxa.3701.1.7

Sherman C, Appeldoorn R, Ballantine D, Bejarano I, Carlo M, Kesling D, Nemeth M, Pagan F, Ruiz H, Schizas NV, Weil E (2013) Exploring the mesophotic zone: Diving operations and scientific highlights of three research cruises across Puerto Rico and US Virgin Islands. In: Lang MA, Sayer MDJ (Eds) Proceedings of the 2013 AAUS/AEDP Curacao Joint International Scientific Diving Symposium, Dauphin Island, AL. American Academy of Underwater Sciences, 297-312.

Smit H (2007) Litarachna brasiliensis n.sp., the first member of the water mite family Pontarachnidae (Acari: Hydrachnidia) from South America. Systematic and Applied Acarology 12: $141-146$.

Wiles PR, Chatterjee T, De Troch M (2002) Two new and one known marine water mite (Acari: Hydrachnidia: Pontarachnidae) from South-East Africa. Journal of Natural History 36: 1987-1994. doi: 10.1080/00222930110068583 